\title{
High serum resistin associates with intrahepatic inflammation and necrosis: an index of disease severity for patients with chronic HBV infection
}

Zhongji Meng ${ }^{1,2+}$, Yonghong Zhang ${ }^{3+}$, Zhiqiang Wei ${ }^{2+}$, Ping Liu ${ }^{1,5}$, Jian Kang ${ }^{1}$, Yinhua Zhang ${ }^{1}$, Deqiang Ma ${ }^{1}$, Changzheng Ke ${ }^{1}$, Yue Chen ${ }^{1}$, Jie Luo ${ }^{4^{*}}$ and Zuojiong Gong ${ }^{5^{*}}$

\begin{abstract}
Background: Studies have revealed that resistin plays a role as an intrahepatic cytokine with proinflammatory activities. This study investigated the association between serum resistin and fibrosis severity and the possible marker role of resistin in the inflammatory process of chronic hepatitis B.

Methods: In this study, 234 subjects with HBV infection were retrospectively selected, including 85 patients with chronic hepatitis B (CHB), 70 patients with HBV-related liver cirrhosis (LC-B), and 79 patients with HBV-related liver failure (LF-B). Serum levels of resistin, IL-1, IL-6, IL-17, IL-23, TNF- $a$, and TGF- $\beta 1$ were assayed by ELISA. Demographic and clinical characteristics of patients were extracted from clinical databases of Taihe Hospital, Hubei University of Medicine, including serum levels of alanine aminotransferase (ALT), aspartate aminotransferase (AST), total bilirubin (TBil), and liver stiffness (LS).

Results: All the selected patients with HBV infection showed significantly increased levels of serum resistin, which was rarely detectable in the healthy controls. Serum resistin levels in patients with CHB, LC-B, and LF-B were $4.119 \pm 5.848 \mathrm{ng} / \mathrm{mL}, 6.370 \pm 6.834 \mathrm{ng} / \mathrm{mL}$, and $6.512 \pm 6.076 \mathrm{ng} / \mathrm{mL}$, respectively. Compared with the CHB group, patients with LC-B or LF-B presented with significantly higher serum levels of resistin $(p<0.01)$. On the other hand, all of the enrolled patients had high serum levels of IL-1, IL-6, IL-17, TNF- $a$, and TGF- $\beta 1$, but not IL-23. Interestingly, serum levels of resistin was significantly positively correlated with serum levels of TGF- $\beta 1$ in LC-B patients $(R=0.3090, p=0.0290)$, with IL-17 in LC-B $(R=0.4022, p=0.0038)$ and LF-B patients $(R=0.5466, p<0.0001)$, and with $\mathrm{AST}(R=0.4501, p=0.0036)$ and $\mathrm{LS}(R=0.3415, p=0.0310)$ in CHB patients.
\end{abstract}

Conclusions: High serum resistin associates with intrahepatic inflammation and necrosis and may be used as an index of disease severity for patients with chronic HBV infection.

Keywords: Resistin, Proinflammatory cytokines, Hepatitis B, Liver cirrhosis, Liver failure

\footnotetext{
*Correspondence: luojie_001@126.com; zjgong@163.com

${ }^{\dagger}$ Equal contributors

${ }^{4}$ Department of Neurology, Taihe Hospital, Hubei University of Medicine,

South Renmin Road. 32, 442000 Shiyan, Hubei, China

${ }^{5}$ Department of Infectious Diseases, Renmin Hospital of Wuhan University,

Zhangzhidong Road. 99, 430060 Wuhan, China

Full list of author information is available at the end of the article
} 


\section{Background}

HBV infection is the most common cause of chronic liver injury and a major cause of liver cirrhosis, hepatocellular carcinoma, and liver failure [1]. Liver failure is a severe clinical syndrome characterized by jaundice, ascites, hepatic encephalopathy, and a bleeding tendency due to impairment of liver function, leading to poor prognosis [2]. According to World Health Organization estimates, approximately 240 million people around the world suffer from chronic HBV infection (http://www.who.int/hiv/ pub/hepatitis/hepatitis-b-guidelines/en/).

The outcomes of HBV infection depend on both viral and host factors, including genetic factors that determine a host's immune mechanisms [3]. It is generally accepted that HBV is not directly cytopathic; thus, HBV-related hepatocellular injuries are the results of the complex interplay among HBVs, hepatocytes, and host immune cells [3, 4]. It has been widely recognized that host immunity contributes to the pathogenesis of liver injuries and even liver failure. The immune clearance of HBV can trigger extensive liver damage that results in fibrosis and cirrhosis. Cytotoxic Tlymphocytes (CTLs), the core of cellular immunity, play a key role in the clearance of intracellular viruses, which are the major cause of cell apoptosis or necrosis [5]. Several studies have characterized intrahepatic $\mathrm{CD} 4^{+}$and $\mathrm{CD}^{+} \mathrm{T}$ lymphocytes in chronic hepatitis $\mathrm{B}$ (CHB) (as reviewed by Shimizu) [6]. It is generally accepted that HBV-specific $\mathrm{CD}^{+} \mathrm{T}$ cells have important functions in controlling HBV replication in the liver without causing hepatic necroinflammation, whereas non-specific CTLs may contribute to HBV-related intrahepatic inflammation [7].

Macrophages Cells play a key role in the homeostasis of the liver, which undergo polarized activation to M1 or M2 or M2-like activation states in response to environmental signals. The M1 phenotype is characterized by the upregulation of proinflammatory cytokines and promotion of Th1 response, and strong microbicidal and tumoricidal activity. In contrast, M2 macrophages promote tissue remodeling and tumor progression, and have immunoregulatory functions (as reviewed by Antonio Sica, et al.) [8]. It is general accepted that HBV promotes intrahepatic resident and recruited macrophages M2 polarization, leading to impairment of host immunity and progression of tissue fibrosis/remodeling [9].

Th cells that produce IL-17 (Th17 cells) have recently been identified as the third subset of effector $\mathrm{T}$ cells, which produce IL-17A, IL-17 F, IL-22 and IL-21 [10]. High numbers of IL-17-producing $\mathrm{CD}^{+} \mathrm{T}$ cells have been observed in both the liver and the blood of $\mathrm{CHB}$ patients; and the elevation in this cell population has been correlated with a high serum level of IL-27 [11]. An increase in circulating and intrahepatic IL-17producing $\mathrm{CD}^{+}{ }^{+} \mathrm{T}$ cells is well correlated with ALT level and liver injury. $\mathrm{CD}^{+} \mathrm{T}$ lymphocytes that produce IL-
17 infiltrate into the livers of patients with $\mathrm{CHB}$ and increase the severity of liver damage [12].

Prior studies on HBV-related hepatitis flares have demonstrated that, high ALT levels usually accompanied by increased serum levels of IL-12 and Th1 phenotypic cytokines (IL-2 and IFN- $\gamma$ ) [13, 14], and the natural killer (NK)-cell mediated liver damage were found to be attributed to the increased serum IFN-a and IL-8 [15]. Therefore, hepatitis B flares are results of complex interplay of the virus and the innate and adaptive immune responses, and the more vigorous immune response against HBV, the higher the serum ALT (as reviewed by Chang and Liaw) [4].

Hepatic microcirculation disorders occur in all chronic liver diseases, which result in insufficient blood supply to hepatocytes. In addition, collateral circulation also depletes blood flow from the liver. As a result, a) nutrients absorbed from the intestines cannot nourish the liver; b) the therapeutic effects of certain drugs are decreased; and c) metabolic wastes accumulate. These events speed the progression of liver diseases.

Resistin is a 12.5-kd adipokine that belongs to a new family of small, cysteine-rich secretory proteins known as FIZZ (found in inflammatory zone) or resistin-like molecules [16]. In rodents, resistin is highly expressed in adipose tissue, and circulating levels of resistin are increased during diet-induced or genetic obesity [17]. It has been verified that resistin is expressed and upregulated under conditions of chronic injury in human liver tissue, and resistin can stimulate human hepatic stellate cells (HSCs) to secrete proinflammatory cytokines through activating the nuclear factor (NF)- $\mathrm{kB}$ signaling pathway [18]. In patients with chronic hepatitis $C$ virus infection, low serum levels of resistin are associated with the presence of fibrosis and may therefore be a biochemical marker of fibrosis [19]. Moreover, Tsochatzis et al. found that in $\mathrm{CHB}$ and chronic hepatitis $\mathrm{C}(\mathrm{CHC})$ patients, resistin levels are independently associated with fibrosis severity [20]. Another study found that elevated levels of resistin were prominent in patients with hepatobiliary inflammation and were associated with breach of self-tolerance; thus, resistin may be an important marker of disease severity in autoantibody-mediated gastrointestinal inflammatory diseases [21]. Furthermore, increased serum resistin is known to be positively correlated with histological inflammatory score in nonalcoholic fatty liver disease (NAFLD), suggesting that increased resistin in NAFLD patients is related to the histological severity of this disease [22].

In the present study, patients with chronic HBV infection were retrospectively selected. The serum resistin levels and serum levels of the cytokines IL-1, IL-6, IL-17, IL-23, TNF- $\alpha$, and TGF- $\beta 1$ were assayed. The association between serum resistin levels and serum cytokine 
Table 1 Clinical characteristics of the enrolled patients

\begin{tabular}{llll}
\hline Demographics & CHB $(n=85)$ & LC-B $(n=70)$ & LF-B $(n=79)$ \\
\hline Male/female & $64 / 21$ & $42 / 28$ & $65 / 14$ \\
Age (years), mean \pm SD & $39.800 \pm 14.900$ & $48.330 \pm 11.050$ & $46.400 \pm 10.000$ \\
HBeAg positive/negative & $47 / 38$ & $26 / 44$ & $30 / 49$ \\
HBV DNA (log10) IU/ml & $6.70 \pm 1.45$ & $6.06 \pm 1.17$ & $6.45 \pm 1.35$ \\
Antivirus treatment (Y/N) & $62 / 23$ & $56 / 14$ & $68 / 11$ \\
ALT (IU/L) & $178.894 \pm 205.229$ & $61.043 \pm 117.280$ & $186.861 \pm 270.105$ \\
AST (IU/L) & $116.865 \pm 146.940$ & $70.171 \pm 114.080$ & $172.730 \pm 219.91$ \\
TBil (mmol/L) & $41.843 \pm 72.044$ & $38.336 \pm 43.166$ & $238.420 \pm 139.550$ \\
\hline
\end{tabular}

levels, liver biochemical indices, and fibrosis severity were analyzed. The possible role of resistin as a marker of the inflammatory process in patients with $\mathrm{CHB}$ was investigated in detail.

\section{Methods}

\section{Patients}

Patients with $\mathrm{CHB}$ were retrospectively selected from Aug. 2013 to Sept. 2014 at the Inpatient Department of Taihe Hospital, Hubei University of Medicine. CHB, HBV-related liver cirrhosis (LC-B), and HBV-related liver failure (LF-B) were diagnosed in accordance with published guidelines $[23,24]$. Patients' serum samples were routinely stored and used for this retrospective study. The inclusion criteria were chronic infection with HBV, defined as detectable HBsAg and HBV-DNA for at least 6 months, and age $\geq 18$ years. Patients were excluded if they were co-infected with the hepatitis A virus (HAV), hepatitis $\mathrm{C}$ virus ( $\mathrm{HCV})$, hepatitis $\mathrm{D}$ virus (HDV), hepatitis $\mathrm{E}$ virus (HEV), or human immunodeficiency virus (HIV); if they reported consuming significant quantities of alcohol (more than $30 \mathrm{~g}$ per week for men and $20 \mathrm{~g}$ per week for women); if they had received a liver allograft; or if a malignant disease, including HCC, had been diagnosed. Clinical databases were consulted to obtain patients' demographic and clinical characteristics, including age; sex; serum levels of alanine aminotransferase (ALT), aspartate aminotransferase (AST), and total bilirubin (TBil); and liver stiffness (LS). The study protocol was approved by the Ethics Committee of Taihe Hospital,Hubei university of Medicine. Written informed consent was given by all the participants prior to their inclusion in this study. All data and samples used were collected during standard clinical care. Twenty serum samples from blood donors were used as healthy controls (HCs).

\section{Quantification of serum levels of resistin}

Serum levels of resistin were measured using ELISA kits (eBioscience, USA) according to the manufacturer's instructions (with resistin sensitivity $<3.1 \mathrm{pg} / \mathrm{mL}$ ).

\section{Quantification of serum levels of IL-1, IL-6, IL-17, IL-23, TNF- $\alpha$ and TGF- $\beta 1$}

Serum levels of IL-1, IL-6, IL-17, IL-23, TNF- $\alpha$, and TGF- $\beta 1$ were measured using ELISA kits (R\&D Systems, USA) in accordance with the manufacturer's instructions. Standard curves were constructed using standard samples (IL-1 $\beta$ sensitivity $<1 \mathrm{pg} / \mathrm{mL}$; IL-6 sensitivity < $0.7 \mathrm{pg} / \mathrm{mL}$; IL-17 sensitivity < $15 \mathrm{pg} / \mathrm{mL}$; IL-23 sensitivity $<16.3 \mathrm{pg} / \mathrm{mL}$; TNF- $\alpha$ sensitivity $<5.5 \mathrm{pg} / \mathrm{mL}$; and TGF$\beta 1$ sensitivity $<15.4 \mathrm{pg} / \mathrm{mL}$ ).

\section{Statistical analyses}

Study data are presented as means \pm SD. Variables were compared using a general linear model, Student's $t$-test, or the Mann-Whitney $U$ test as needed. Statistical analysis was performed using SPSS for Windows. Simple linear correlation analyses were conducted using Pearson's method to assess the correlations between resistin and

Table 2 Serum levels of resistin and cytokines

\begin{tabular}{llccc}
\hline Groups & HC & CHB & LC-B & LF-B \\
\hline Resistin $(\mathrm{ng} / \mathrm{mL})$ & $0.078 \pm 0.270$ & $4.119 \pm 5.848$ & $6.370 \pm 6.834$ & $6.512 \pm 6.076$ \\
IL-1 $(\mathrm{pg} / \mathrm{mL})$ & $0.077 \pm 0.186$ & $0.549 \pm 1.341$ & $0.932 \pm 1.754$ & $0.446 \pm 1.104$ \\
IL-6 $(\mathrm{pg} / \mathrm{mL})$ & $0.077 \pm 0.186$ & $8.830 \pm 19.426$ & $21.822 \pm 50.372$ & $29.792 \pm 51.394$ \\
IL-17 $(\mathrm{pg} / \mathrm{mL})$ & $2.923 \pm 2.310$ & $5.410 \pm 5.634$ & $5.164 \pm 3.522$ & $5.288 \pm 5.860$ \\
IL-23 $(\mathrm{pg} / \mathrm{mL})$ & $4.589 \pm 3.823$ & $8.149 \pm 17.379$ & $6.103 \pm 12.005$ & $5.874 \pm 10.981$ \\
TNF- $-\alpha(\mathrm{pg} / \mathrm{mL})$ & $2.489 \pm 2.083$ & $9.038 \pm 8.108$ & $27.961 \pm 120.362$ & $43.472 \pm 145.516$ \\
TGF- $\beta 1(\mathrm{pg} / \mathrm{mL})$ & $29.380 \pm 3.339$ & $46.205 \pm 7.818$ & $48.636 \pm 11.555$ & $55.537 \pm 6.971$ \\
\hline
\end{tabular}


cytokines, AST, and TBil. The threshold used for statistical significance was $p<0.05$. The statistical methods of this study were reviewed by Dr. Jing Wang from the Department of Epidemiology and Hygenic statistics, Hubei University of Medicine.

\section{Results}

Patient characteristics

After applying the criteria described above, 234 patients were selected for the present study: 85 patients with CHB, 70 patients with LC-B, and 79 patients with LF-B. Baseline characteristics of these patients are summarized in Table 1. The male/female ratios for $\mathrm{CHB}$ patients, $\mathrm{LC}$ B patients, and LF-B patients were 64/21, 42/28, and 65/ 14 , respectively. Most patients received NA-based antiviral treatment, in which entecavir is most used, except that some CHB patients received IFN- $\alpha$ treatment. Serum levels of ALT, AST, and TBil were 178.894 $\pm 205.229 \mathrm{IU} / \mathrm{L}$, $116.865 \pm 146.940 \mathrm{IU} / \mathrm{L}$, and $41.843 \pm 72.044 \mathrm{mmol} / \mathrm{L}$, respectively, for $\mathrm{CHB}$ patients; $61.043 \pm 117.280 \mathrm{IU} / \mathrm{L}$, $70.171 \pm 114.080 \mathrm{IU} / \mathrm{L}$, and $38.336 \pm 43.166 \mathrm{mmol} / \mathrm{L}$, respectively, for LC-B patients; and 86.861 $\pm 270.105 \mathrm{IU} / \mathrm{L}$, $172.730 \pm 219.91 \mathrm{IU} / \mathrm{L}$, and $238.420 \pm 139.550 \mathrm{mmol} / \mathrm{L}$, respectively, for LF-B patients (Table 2). The primary analyses of this study focused on serum levels of resistin, IL-1, IL-6, IL-17, IL-23, TNF- $\alpha$ and TGF- $\beta 1$, which were generally determined using serum samples obtained upon patients' initial presentation in the Department of Infectious Diseases, Taihe Hospital, Hubei University of Medicine.

\section{Patients with chronic HBV infection had significantly elevated serum resistin levels}

Serum resistin was rarely detectable in the $\mathrm{HC}$ group $(0.078 \pm 0.270)$. In contrast, high serum resistin levels were detected in patients with CHB $(4.119 \pm 5.848)$, LCB $(6.370 \pm 6.834)$, and LF-B $(6.512 \pm 6.076)$ (Table 1, Fig. 1). Compared with CHB patients, LC-B patients and LF-B patients had significantly higher serum levels of resistin $(p<0.01)$, whereas LC-B patients and LF-B patients did not significantly differ with respect to serum resistin levels $(p>0.05)$ (Fig. 1).

\section{Patients with chronic HBV infection had significantly} increased serum levels of IL-1, IL-6, IL-17, TNF- $a$, and TGF$\beta 1$, but not IL-23

With respect to cytokine detection, serum IL-1 and IL-6 were below the detection limit in HCs, whereas IL-17 $(2.923 \pm 2.310 \mathrm{pg} / \mathrm{mL}), \quad$ IL-23 $(4.589 \pm 3.823 \mathrm{pg} / \mathrm{mL})$, TNF- $\alpha(2.489 \pm 2.083 \mathrm{pg} / \mathrm{mL})$, and TGF- $\beta 1$ (29.380 \pm $3.339 \mathrm{pg} / \mathrm{mL}$ ) were detected in these subjects. Compared with HCs, patients with $\mathrm{CHB}, \mathrm{LC}-\mathrm{B}$, or LF-B had elevated levels of IL-1, IL-6, IL-17, TNF- $\alpha$, and TGF- $\beta 1$ (Table 1, Fig. 2). Serum IL-1 levels were higher in LC-B patients $(0.932 \pm 1.754 \mathrm{pg} / \mathrm{mL})$ than in $\mathrm{CHB}$ patients

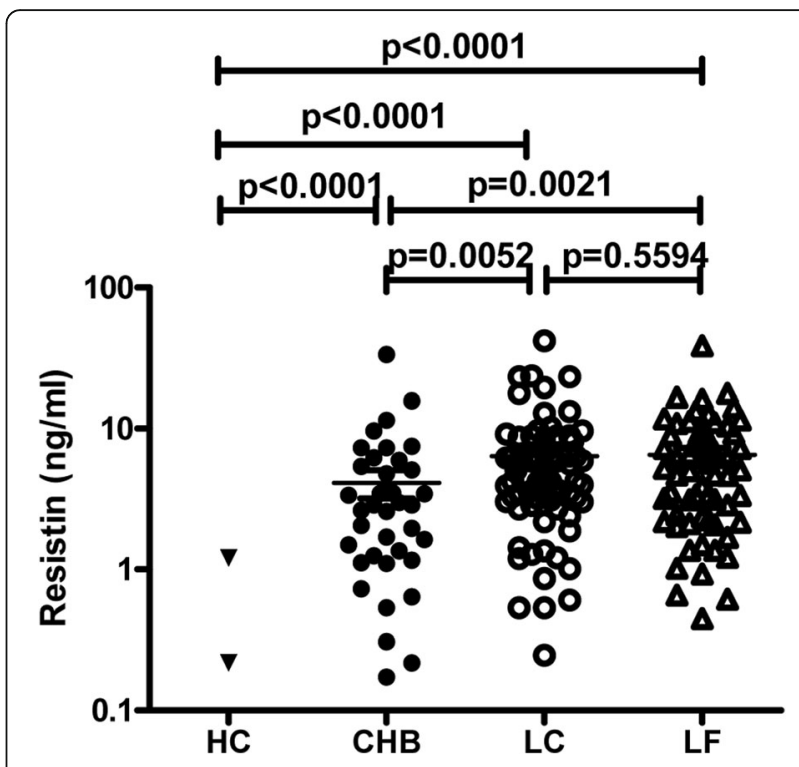

Fig. 1 Serum levels of resistin in patients with HBV infection. Serum resistin levels were assayed by ELISA and analyzed using GraphPad software. Differences between different groups and HCs were assessed using the Mann-Whitney test. HC, healthy control; CHB, chronic hepatitis B; LC, liver cirrhosis; LF, liver failure

$(0.549 \pm 1.341 \mathrm{pg} / \mathrm{mL})$ and LF-B patients $(p<0.001)$ (Fig. 2a). LC-B patients (21.822 $\pm 50.372 \mathrm{pg} / \mathrm{mL})$ and LF$\mathrm{B}$ patients $(29.792 \pm 51.394 \mathrm{pg} / \mathrm{mL})$ had markedly higher serum IL-6 levels than CHB patients $(p<0.001)$, whereas the serum IL-6 levels of LC-B patients and LF-B patients did not significantly differ $(p>0.05)$ (Fig. 2b). All patients had high serum IL-17 and TNF- $\alpha$ levels, with no significant differences in these cytokines among $\mathrm{CHB}$ patients, LC-B patients, and LF-B patients $(p>0.05)$ (Fig. $2 \mathrm{c}$ and e). Serum TGF- $\beta 1$ levels were higher in LFB patients $(55.537 \pm 6.971 \mathrm{pg} / \mathrm{mL})$ than in $\mathrm{CHB}$ patients $(46.205 \pm 7.818 \mathrm{pg} / \mathrm{mL})$ and LC-B patients (48.636 \pm $11.555 \mathrm{pg} / \mathrm{mL})(p<0.001)$ (Fig. 2f). Average serum IL-23 levels were higher for patients than for HCs but did not significantly differ among CHB patients, LC-B patients, and LF-B patients $(p>0.05)$ (Fig. 2d).

Serum resistin was positively correlated with serum IL-17 among patients with LC-B or LF-B

Among all patients with chronic HBV infection, serum resistin was positively correlated with serum IL-17 $(R=0.4121, p<0.0001)$ (Fig. 3a). Further analysis demonstrated that serum resistin was strongly positively correlated with serum IL-17 among LF-B patients $(R=0.5466, p<0.0001) \quad$ (Fig. 3d), more weakly positively correlated with serum IL-17 among LC-B patients $(R=0.4022, p=0.0038)$ (Fig. $3 \mathrm{c})$, and not correlated with serum IL-17 among CHB patients $(R=0.0102, p=0.9560)$ (Fig. 3b). 

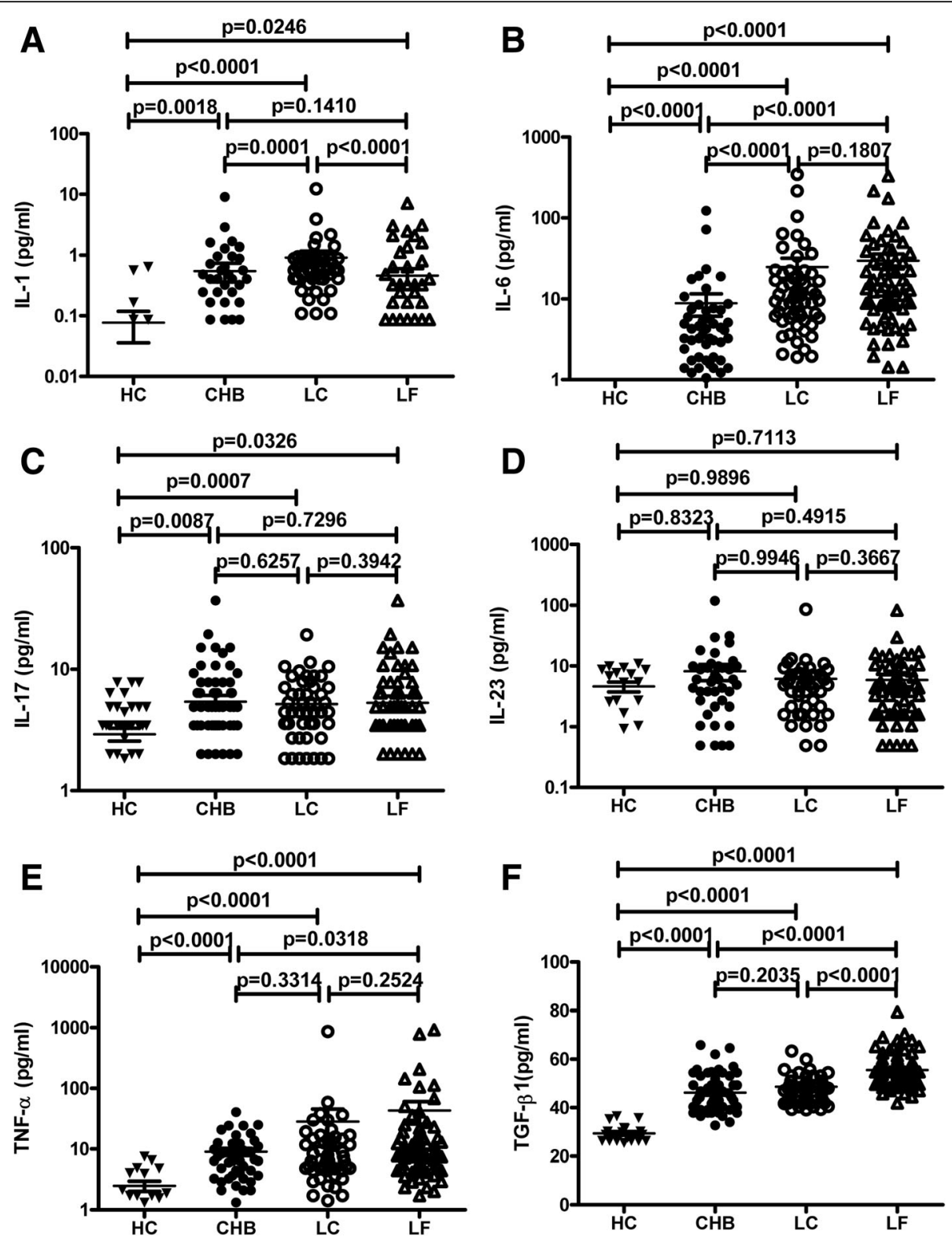

Fig. 2 Serum levels of IL-1, IL-6, IL-17, IL-23, TNF-a, and TGF- $\beta 1$ in patients with HBV infection. Serum levels of IL-1 (a), IL-6 (b), IL-17 (c), IL-23 (d), TNF-a (e), and TGF- $\beta 1$ (f) were assayed by ELISA and analyzed using GraphPad software. Differences between different groups and HCs were assessed using the Mann-Whitney test. HC, healthy control; CHB, chronic hepatitis B; LC, liver cirrhosis; LF, liver failure

Serum resistin was positively correlated with serum TGF$\beta 1$ in patients with LC-B

Subsequently, the relationship between serum resistin and serum TGF- $\beta 1$ was analyzed. Positive correlations between serum resistin and serum TGF- $\beta 1$ were observed for all patients with chronic HBV infection $(R=0.2251, p=0.0073) \quad$ (Fig. 4a). Subgroup analysis indicated that serum resistin was weakly positively correlated with serum TGF- $\beta 1$ among LC-B patients $(R=0.3090, p=0.0290)$ (Fig. $4 \mathrm{~b})$. Serum resistin was not correlated with serum TGF- $\beta 1$ among $\mathrm{CHB}$ patients and LF-B patients (data not shown).

Serum resistin levels were positively correlated with LS in patients with $\mathrm{CHB}$

The relationship between serum resistin levels and LS was also analyzed. A weak positive correlation with LS was found among all patients with HBV infection $(R=0.1374, p=0.0445)$ (Fig. 5a). In subgroup 

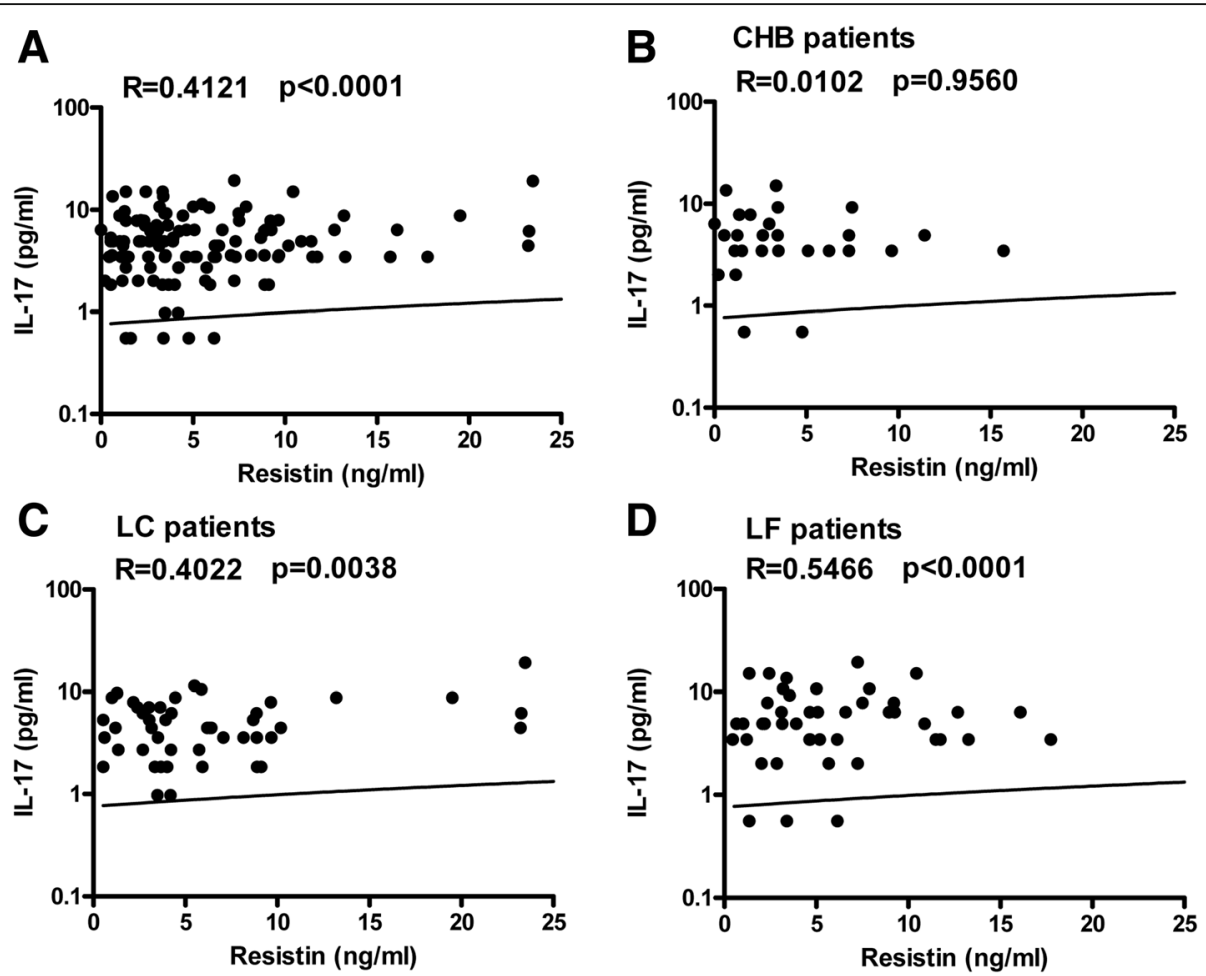

Fig. 3 The relationship between serum resistin and serum IL-17. Serum resistin levels and serum IL-17 levels were analyzed by correlation analysis using GraphPad software. The correlations between resistin levels and serum IL-17 levels among all hepatitis B patients (a), CHB patients (b), LC-B patients (c), and LF-B patients (d) are presented. CHB, chronic hepatitis B; LC, liver cirrhosis; LF, liver failure

analysis, this correlation was only found among $\mathrm{CHB}$ patients $(R=0.3415, \quad p=0.0310) \quad$ (Fig. 5b). Serum resistin levels were not correlated with LS among LC-B patients or LF-B patients (data not shown).

Serum resistin was positively correlated with serum AST in patients with $\mathrm{CHB}$

The relationships between serum resistin and serum ALT, AST, and TBil were also analyzed. A positive correlation between serum resistin and serum AST was observed among $\mathrm{CHB}$ patients $(R=0.4501, p=0.0036)$
(Fig. 6). Serum resistin was not correlated with serum AST among LC-B patients or LF-B patients; in addition, no correlations between serum resistin and serum ALT or TBil were detected either among all enrolled patients or in any examined subgroup (data not shown).

\section{Discussion}

This study revealed that patients with chronic HBV infection had significantly elevated serum resistin levels; this finding is consistent with previously reported data [20]. Patients with LC-B or LF-B had significantly higher
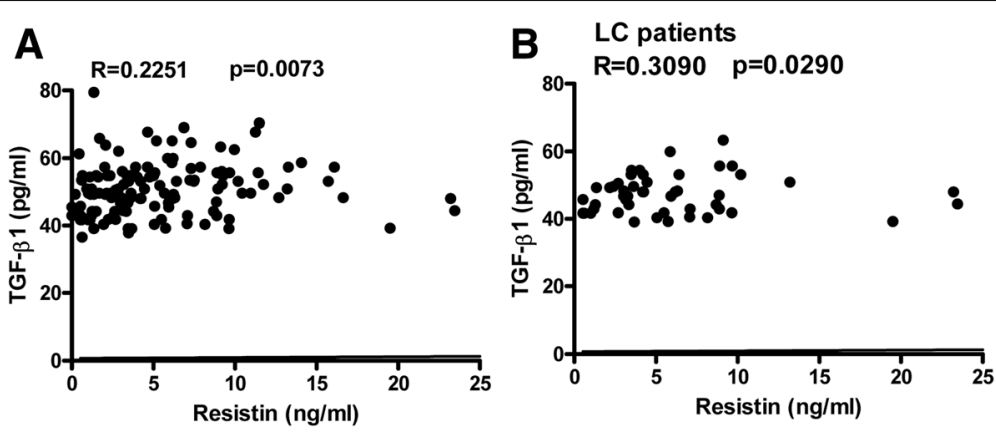

Fig. 4 The relationship between serum resistin and serum TGF- $\beta 1$. Serum resistin levels and serum TGF- $\beta 1$ levels were analyzed by correlation analysis using GraphPad software. The correlations between resistin levels and serum TGF- $\beta 1$ levels among all hepatitis B patients (a) and LC-B patients $(\mathbf{b})$ are presented. LC, liver cirrhosis 

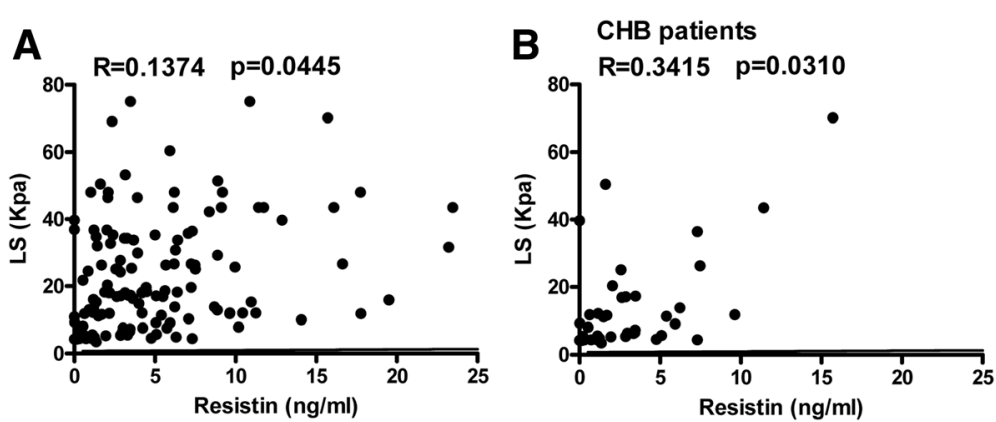

Fig. 5 The relationship between serum resistin and LS. Serum resistin levels and LS values were analyzed by correlation analysis using GraphPad software. The correlation between resistin levels and LS among all hepatitis B patients (a) and CHB patients (b) are presented. CHB, chronic hepatitis $B$

serum resistin levels than $\mathrm{CHB}$ patients $(p<0.01)$, whereas LC-B patients and LF-B patients did not significantly differ with respect to serum resistin levels $(p>0.05)$. These results suggest that serum resistin could play a role as an indicator of disease severity and/ or degeneration in patients with hepatitis B. Moreover, high serum levels of IL-1, IL-6, IL-17, TNF- $\alpha$, and TGF$\beta 1$ but not IL-23 were detected in CHB, LC-B, and LF-B patients. Serum IL-1 levels were higher in LC-B patients than in CHB and LF-B patients, whereas serum IL-6 and TNF- $\alpha$ levels were much higher for LC-B patients and LF-B patients than for $\mathrm{CHB}$ patients; these findings are consistent with the inflammatory roles of the proinflammatory cytokines IL-1, IL-6, and TNF- $\alpha$ [25].

In this study, serum resistin levels were weakly correlated with LS values determined by FibroScan among CHB patients but not among LC-B patients or LF-B patients. This result can be explained by the fact that LS

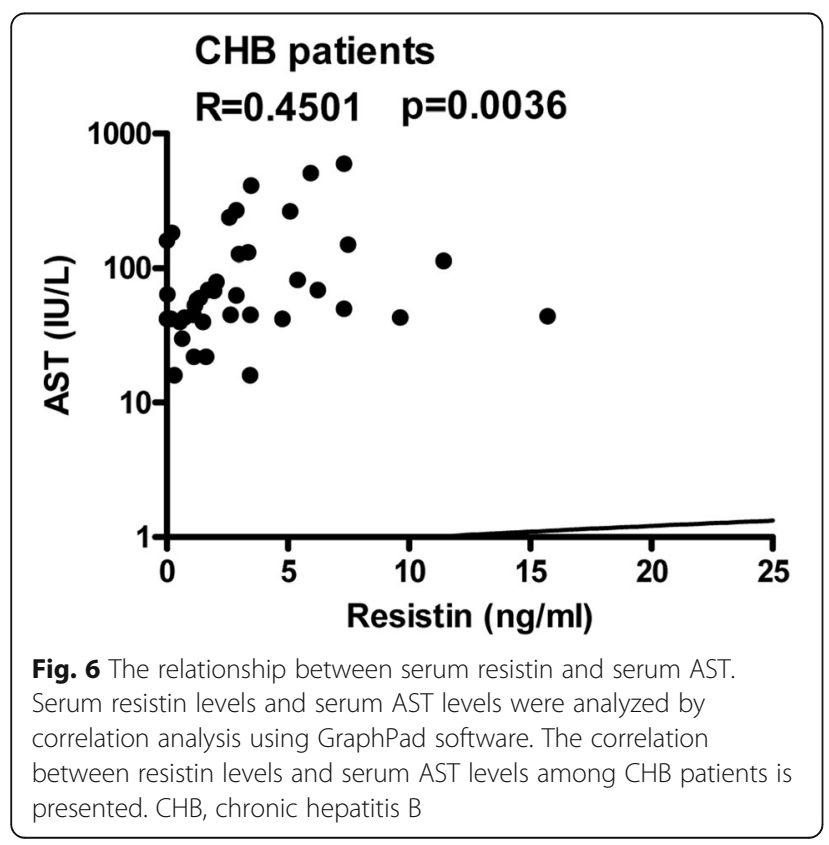

depends on the extent of fibrosis due to prior intrahepatic deposits [26]. Serum markers such as procollagen peptide, matrix metalloproteinases (MMPs), tissue inhibitors of matrix metalloproteinases (TIMPs), laminins, and TGF- $\beta 1$, are correlated with molecules derived directly from the ECM or produced by activated HSCs. Thus, the elevation of these serum markers suggests the activation of fibrogenesis [27, 28]. Interestingly, serum resistin levels were positively correlated with serum TGF- $\beta 1$ levels, particularly among LC-B patients (Fig. 4). Furthermore, among $\mathrm{CHB}$ patients, serum resistin levels were positively correlated with serum AST levels (Fig. 5). These results are consistent with the general notion that resistin can act as an intrahepatic cytokine with proinflammatory activity in $\mathrm{HSCs}$ via a $\mathrm{Ca} 2^{+} / \mathrm{NF}-\mathrm{kB}^{-}$ dependent pathway and involvement in the pathophysiology of liver fibrosis [18].

IL-17 is a major effector cytokine secreted by Th17 cells, which play a proinflammatory role in the pathogenesis of hepatitis $\mathrm{B}$ and promote HBV infectionrelated injury [29]. In this study, all patients with $\mathrm{CHB}$, LC-B, or LF-B exhibited similarly elevated serum IL-17 levels (Fig. 2c). There were no significant correlations between serum IL-17 and serum ALT, AST, or TBil (data not shown). Serum IL-17 was positively correlated with serum resistin among $\mathrm{LC}-\mathrm{B}$ patients and LF-B patients but not among $\mathrm{CHB}$ patients (Fig. 3); these findings provide additional evidence supporting the proinflammatory role of IL-17, especially in the context of advanced liver injury.

Recently, Ming et al. found that the upregulation of the TGF- $\beta 1 / \mathrm{IL}-31$ pathway is associated with disease severity in LC-B, since elevated serum TGF- $\beta 1$ and IL-31 levels were positively associated with albumin, alphafetoprotein, creatinine, white blood cell, and platelet levels among LC-B patients [30]. Furthermore, TGF- $\beta 1 /$ IL-31 pathway may also play an important role in the pathogenesis of liver injury during chronic $\mathrm{HBV}$ infection, since increased activity of the TGF- $\beta 1 / \mathrm{IL}-31$ 
pathway has been found well correlated with the extent of liver injury, disease severity, and nonsurvival among ACLF patients, whereas reduced activity of this pathway has been detected during the recovery from liver injury in $\mathrm{CHB}$ cases [31]. In the current study, patients with HBV chronic infection exhibited elevated serum TGF$\beta 1$, and serum TGF- $\beta 1$ levels were significantly higher in LF-B patients than in CHB patients or LC-B patients. CHB and LC-B patients did not significantly differ with respect to serum TGF- $\beta 1$, although average serum TGF$\beta 1$ levels were slightly higher in LC-B patients than in $\mathrm{CHB}$ patients. These results provided additional data to support the potential role of TGF- $\beta 1$ in the pathogenesis of liver injury in patients with chronic HBV infection, particularly patients with LF-B.

IL-23 has recently been identified as playing a critical role in a number of chronic inflammatory diseases. Xia et al. reported that both serum IL-23 level and hepatic IL-23 were positively correlated with liver injury in $\mathrm{CHB}$ patients [32]. In this study, average serum IL-23 levels were higher in patients than in $\mathrm{HCs}$ and were markedly higher in $\mathrm{CHB}$ patients than in $\mathrm{HCs}(8.149$ vs. 4.589$)$, with no significant differences in serum IL-23 levels among CHB patients, LC$B$ patients, and LF-B patients. This lack of significance may be attributable to the large deviations detected in serum IL23 levels (which ranged from 0.49 to 118.92).

Taken together, the findings of this study demonstrated that high serum resistin was positively correlated with serum IL-17 and TGF- $\beta 1$. Elevated resistin is associated with the inflammation and necrosis of liver cells and could therefore potentially be used as an index of disease severity and degeneration in patients with chronic HBV infection. However, the mechanism of resistin in the inflammatory process of chronic hepatitis B is unclear, further studies are needed to elucidate how resistin works in the progress of liver injury, and the cross-talk between resistin and IL-17 or TGF- $\beta$ signaling pathways.

\section{Conclusions}

High serum resistin associates with intrahepatic inflammation and necrosis and may be used as an index of disease severity for patients with chronic HBV infection.

\section{Additional file}

Additional file 1: The raw data of laboratory tests for serum levels of resistin, IL-1, IL-6, IL-17, IL-23, TNF-a, TGF- $\beta 1$, ALT, AST and TBil. (XLS 157 kb)

\section{Abbreviations}

ALT: Alanine aminotransferase; AST: Aspartate aminotransferase; CHB: Chronic hepatitis B; CTL: Cytotoxic T-lymphocyte; ELISA: Enzyme-linked immunobsorbent assay; HBV: Hepatitis B virus; HSC: Hepatic stellate cells; LC: Liver cirrhosis; LF: Liver failure; LS: Liver stiffness; NAFLD: Nonalcoholic fatty liver disease; TGF- $\beta$ : Transforming growth factors beta; TNF-a: Tumor necrosis factor alpha

\section{Acknowledgements}

The authors thank Yuling He and Yingqi Huang for excellent technical assistance.

\section{Funding}

This work was partly supported by the National Key Program for Infectious Disease of China (2013ZX10002-001), the Natural Science Foundation of Hubei Province of China (2014CFB645 and 2010CDZ036), the Natural Science Foundation of Hubei Provincial Department of Education (Z20102101), and the Foundation for Innovative Research Team of Hubei University of Medicine (2014CXG05).

\section{Availability of data and materials}

The raw data analyzed in the present study are included in a (Additional file 1).

\section{Authors' contributions}

$\mathrm{MZJ}$ and $\mathrm{ZYH1}$ contributed equally to this work; MZJ, ZYH, CY, LJ and GZJ participated in the design of the study and performed the statistical analysis; $Z Y H 1$, WZQ, LP, KJ, ZYHZ2, MDQ and KCZ carried out the ELISAs; MZ and WZQ contributed new reagents; MZ, WZQ and LP analyzed the data; MZJ, $C Y, \sqcup$ and GZJ conceived of the study, and participated in its design and coordination and helped to draft the manuscript. All authors read and approved the final manuscript.

\section{Competing interests}

The authors declare that they have no competing interests.

\section{Consent for publication}

Not applicable.

\section{Ethics approval and consent to participate}

The study protocol was approved by the Ethics Committee of Taihe Hospital,Hubei university of Medicine. Written informed consent was given by all the participants prior to their inclusion in this study. All data and samples used were collected during standard clinical care.

\section{Author details}

'Department of Infectious Diseases, Taihe Hospital, Hubei University of Medicine, Shiyan, China. ${ }^{2}$ Institute of Biomedicine, Taihe Hospital, Hubei University of Medicine, Shiyan, China. Institute of Wudang Chinese Medicine, Taihe Hospital, Hubei University of Medicine, Shiyan, China. ${ }^{4}$ Department of Neurology, Taihe Hospital, Hubei University of Medicine, South Renmin Road. 32, 442000 Shiyan, Hubei, China. ${ }^{5}$ Department of Infectious Diseases, Renmin Hospital of Wuhan University, Zhangzhidong Road. 99, 430060 Wuhan, China.

Received: 10 June 2016 Accepted: 8 December 2016

Published online: 07 January 2017

References

1. Trepo C, Chan HL, Lok A. Hepatitis B virus infection. Lancet. 2014;384(9959): 2053-63.

2. Sugawara K, Nakayama N, Mochida S. Acute liver failure in Japan: definition, classification, and prediction of the outcome. J Gastroenterol. 2012;47(8):849-61.

3. Wu JF, Chang MH. Natural history of chronic hepatitis B virus infection from infancy to adult life - the mechanism of inflammation triggering and longterm impacts. J Biomed Sci. 2015;22:92.

4. Chang ML, Liaw YF. Hepatitis B flares in chronic hepatitis B: pathogenesis, natural course, and management. J Hepatol. 2014;61(6):1407-17.

5. Balmasova IP, Yushchuk ND, Mynbaev OA, Alla NR, Malova ES, Shi Z, Gao CL. Immunopathogenesis of chronic hepatitis B. World J Gastroenterol. 2014; 20(39):14156-71.

6. Shimizu Y. T cell immunopathogenesis and immunotherapeutic strategies for chronic hepatitis B virus infection. World J Gastroenterol. 2012;18(20):2443-51.

7. Maini MK, Boni C, Lee CK, Larrubia JR, Reignat S, Ogg GS, King AS, Herberg J, Gilson $\mathrm{R}$, Alisa A, et al. The role of virus-specific CD8(+) cells in liver damage and viral control during persistent hepatitis B virus infection. J Exp Med. 2000; 191(8):1269-80.

8. Sica A, Invernizzi P, Mantovani A. Macrophage plasticity and polarization in liver homeostasis and pathology. Hepatology. 2014;59(5):2034-42.

9. Bility MT, Cheng L, Zhang Z, Luan Y, Li F, Chi L, Zhang L, Tu Z, Gao Y, Fu Y, et al. Hepatitis $B$ virus infection and immunopathogenesis in a humanized 
mouse model: induction of human-specific liver fibrosis and M2-like macrophages. PLoS Pathog. 2014;10(3):e1004032.

10. Zhao L, Qiu DK, Ma X. Th17 cells: the emerging reciprocal partner of regulatory T cells in the liver. J Dig Dis. 2010;11(3):126-33.

11. Zhang GL, Xie DY, Ye YN, Lin CS, Zhang XH, Zheng YB, Huang ZL, Peng L, Gao ZL. High level of IL-27 positively correlated with Th17 cells may indicate liver injury in patients infected with HBV. Liver Int. 2014;34(2):266-73.

12. Zhang JY, Zhang Z, Lin F, Zou ZS, Xu RN, Jin L, Fu JL, Shi F, Shi M, Wang HF, et al. Interleukin-17-producing CD4(+) T cells increase with severity of liver damage in patients with chronic hepatitis B. Hepatology. 2010;51(1):81-91.

13. Takehara T, Hayashi N, Katayama K, Kasahara A, Fusamoto H, Kamada T. Hepatitis B core antigen-specific interferon gamma production of peripheral blood mononuclear cells during acute exacerbation of chronic hepatitis B. Scand J Gastroenterol. 1992;27(9):727-31.

14. Leifeld L, Cheng S, Ramakers J, Dumoulin FL, Trautwein C, Sauerbruch T, Spengler U. Imbalanced intrahepatic expression of interleukin 12, interferon gamma, and interleukin 10 in fulminant hepatitis B. Hepatology. 2002;36(4 Pt 1):1001-8.

15. Dunn C, Brunetto M, Reynolds G, Christophides T, Kennedy PT, Lampertico P, Das A, Lopes AR, Borrow P, Williams K, et al. Cytokines induced during chronic hepatitis B virus infection promote a pathway for NK cell-mediated liver damage. J Exp Med. 2007;204(3):667-80.

16. Steppan CM, Brown EJ, Wright CM, Bhat S, Banerjee RR, Dai CY, Enders GH, Silberg DG, Wen $X, W u$ GD, et al. A family of tissue-specific resistin-like molecules. Proc Natl Acad Sci U S A. 2001;98(2):502-6.

17. Steppan CM, Bailey ST, Bhat S, Brown EJ, Banerjee RR, Wright CM, Patel HR, Ahima RS, Lazar MA. The hormone resistin links obesity to diabetes. Nature. 2001:409(6818):307-12

18. Bertolani C, Sancho-Bru P, Failli P, Bataller R, Aleffi S, DeFranco R, Mazzinghi $B$, Romagnani $P$, Milani $S$, Gines $P$, et al. Resistin as an intrahepatic cytokine: overexpression during chronic injury and induction of proinflammatory actions in hepatic stellate cells. Am J Pathol. 2006;169(6):2042-53.

19. Tiftikci A, Atug O, Yilmaz Y, Eren F, Ozdemir FT, Yapali S, Ozdogan O, Celikel CA, Imeryuz N, Tozun N. Serum levels of adipokines in patients with chronic HCV infection: relationship with steatosis and fibrosis. Arch Med Res. 2009; 40(4):294-8

20. Tsochatzis E, Papatheodoridis GV, Hadziyannis E, Georgiou A, Kafiri G, Tiniakos DG, Manesis EK, Archimandritis AJ. Serum adipokine levels in chronic liver diseases: association of resistin levels with fibrosis severity. Scand J Gastroenterol. 2008;43(9):1128-36.

21. Bostrom EA, Ekstedt M, Kechagias S, Sjowall C, Bokarewa MI, Almer S. Resistin is associated with breach of tolerance and anti-nuclear antibodies in patients with hepatobiliary inflammation. Scand J Immunol. 2011;74(5):463-70

22. Pagano C, Soardo G, Pilon C, Milocco C, Basan L, Milan G, Donnini D, Faggian D, Mussap M, Plebani M, et al. Increased serum resistin in nonalcoholic fatty liver disease is related to liver disease severity and not to insulin resistance. J Clin Endocrinol Metab. 2006:91(3):1081-6.

23. Chinese Society of Hepatology and Chinese Society of Infectious Diseases, Chinese Medical Association. The guideline of prevention and treatment for chronic hepatitis B (2010 version). Zhonghua Gan Zang Bing Za Zhi. 2011; 19(1):13-24.

24. Organization Committee of 13th Asia-Pacific Congress of Clinical Microbiology and Infection. 13th Asia-pacific congress of clinical microbiology and infection consensus guidelines for diagnosis and treatment of liver failure. Hepatobiliary Pancreat Dis Int. 2013;12(4):346-54.

25. Zhang W, Yue B, Wang GQ, Lu SL. Serum and ascites levels of macrophage migration inhibitory factor, TNF-alpha and IL-6 in patients with chronic virus hepatitis B and hepatitis cirrhosis. Hepatobiliary Pancreat Dis Int. 2002;1(4):577-80

26. Ding D, Li H, Liu P, Chen L, Kang J, Zhang Y, Ma D, Chen Y, Luo J, Meng Z. FibroScan, aspartate aminotransferase and alanine aminotransferase ratio (AAR), aspartate aminotransferase to platelet ratio index (APRI), fibrosis index based on the 4 factor (FIB-4), and their combinations in the assessment of liver fibrosis in patients with hepatitis B. Int J Clin Exp Med. 2015;8(11):20876-82.

27. Soresi M, Giannitrapani L, Cervello M, Licata A, Montalto G. Non invasive tools for the diagnosis of liver cirrhosis. World J Gastroenterol. 2014;20(48):18131-50

28. Liu T, Wang X, Karsdal MA, Leeming DJ, Genovese F. Molecular serum markers of liver fibrosis. Biomark Insights. 2012;7:105-17.
29. Huang Z, van Velkinburgh JC, Ni B, Wu Y. Pivotal roles of the interleukin-23/ T helper 17 cell axis in hepatitis B. Liver Int. 2012;32(6):894-901.

30. Ming D, Yu X, Guo R, Deng Y, Li J, Lin C, Su M, Lin Z, Su Z. Elevated TGFbeta1/IL-31 pathway is associated with the disease severity of hepatitis B virus-related liver cirrhosis. Viral Immunol. 2015;28(4):209-16.

31. Yu X, Guo R, Ming D, Deng Y, Su M, Lin C, Li J, Lin Z, Su Z. The transforming growth factor beta1/interleukin-31 pathway is upregulated in patients with hepatitis B virus-related acute-on-chronic liver failure and is associated with disease severity and survival. Clin Vaccine Immunol. 2015;22(5):484-92.

32. Xia L, Tian D, Huang W, Zhu H, Wang J, Zhang Y, Hu H, Nie Y, Fan D, Wu K Upregulation of $\mathrm{IL}-23$ expression in patients with chronic hepatitis $\mathrm{B}$ is mediated by the HBX/ERK/NF-kappaB pathway. J Immunol. 2012;188(2):753-64.

\section{Submit your next manuscript to BioMed Central and we will help you at every step:}

- We accept pre-submission inquiries

- Our selector tool helps you to find the most relevant journal

- We provide round the clock customer support

- Convenient online submission

- Thorough peer review

- Inclusion in PubMed and all major indexing services

- Maximum visibility for your research

Submit your manuscript at www.biomedcentral.com/submit
) Biomed Central 